\title{
DESENVOLVENDO A MATEMÁTICA COMO INSTRUMENTO PARA A PRESERVAÇÃO DO MEIO AMBIENTE
}

\author{
DUARTE, Paulo César Xavier ${ }^{1}$ \\ GARCIA, Letícia Couto ${ }^{2}$ \\ LIMA, Áudria Eliza de ${ }^{3}$ \\ MEYER, Viviane Mara da Silva ${ }^{3}$ \\ SILVA, Natália de Almeida ${ }^{3}$
}

\begin{abstract}
RESUMO: O objetivo deste artigo é apresentar conceitos relativos ao meio ambiente e ressaltar a importância da abordagem da Educação Ambiental por meio da disciplina Matemática. Baseado nisso, buscou-se responder o seguinte questionamento: Como a Matemática pode contribuir para a Educação Ambiental? O desenvolvimento desta pesquisa ocorreu, durante todo o ano letivo de 2011, com alunos da graduação em Licenciatura em Matemática da Universidade do Vale do Sapucaí- Pouso Alegre- MG e com um bolsista da FAPEMIG desta mesma universidade, A metodologia trabalhada é a pesquisa bibliográfica aliada a resolução de problemas e como fundamentação teórica, foram utilizados os PCN (1997), além de obras de diversos teóricos que salientam a relevância do estudo deste tema. O que pode ser observado através deste artigo é que a utilização da Matemática como ferramenta para o estudo de problemas envolvendo questões ambientais auxilia os educandos a estabelecer relação entre a Matemática escolar e a Matemática presente nas questões ambientais, contribuindo, dessa maneira, para que os estudantes tornem-se cidadãos críticos e participativos para aturarem no meio ambiente em que vivem.
\end{abstract}

Palavras-chave: Meio ambiente. Educação matemática. Cidadania.

SUMMARY: The aim of this article is to present concepts related to the environment and highlight the importance of Environmental Education approach through Mathematics. Based on that, the answer to this questioned has been searched: How does Mathematics contribute to Environmental Education? The development of this research occurred through bibliographical studies which had to do with environmental issues, the temas transversais , the problem resolution methodology and the mathematical concepts studied. As theoretical foundation, it was used the PCN (1997), and others which emphasize the relevance of this research. It was observed through this article that the use of Mathematics as a tool for the problem studies concerning to environmental issues assists students to establish a relation between the Mathematics from schools and the Mathematics within environmental studies. This leads to students being critical citizens and participants of the environment they live in.

Keywords: Environment. Mathematics education. Citizenship.

\section{INTRODUÇÃO}

Analisando a situação atual do mundo em que vivemos, torna-se necessário que nos apropriemos de inúmeros conhecimentos para a compreensão das questões ambientais. Dentre essa gama de assuntos a serem considerados, destaca-se aqui a Matemática, a qual nos fornece subsídios qualitativos e também quantitativos para uma visão crítica do meio ambiente, possibilitando-nos, assim, intervir e tomar decisões necessárias quanto a problemas com aspectos ambientais, bem como à quantificação dos problemas envolvidos. (PCN, 1996).

\footnotetext{
${ }^{1}$ Doutorando e Mestre em Educação Matemática pela UNESP, de Rio Claro-SP. Professor Assistente de Tempo Integral do Departamento de Matemática da UNIVÂS- Universidade do Vale do Sapucaí- Pouso Alegre- MG.

${ }^{2}$ Aluna do Curso de Licenciatura em Ciências Biológicas da Universidade do Vale do Sapucaí- UNIVÁS- MGPouso Alegre- MG

${ }^{3}$ Egresso do Curso de Licenciatura em Matemática da Univ. do Vale do Sapucaí- UNIVÁS.Pouso Alegre- MG
} 
Isso nos remete a Carta da Terra, a qual

Considera a pobreza, a degradação ambiental, a injustiça social, os conflitos étnicos, a paz, a democracia, a ética e a crise espiritual como problemas interdependentes que demandam soluções includentes. Ela representa um grito de urgência face às ameaças que pesam, sobre a biosfera e o projeto planetário humano. Significa também um libelo em favor da esperança de um futuro comum da Terra e Humanidade (BOFF, apud CARTA DA TERRA).

Devido a essa iminente urgência, poderemos utilizar a matemática como instrumento de estudo para a educação ambiental, fato que faz com que se exercite a cidadania nos alunos. E isso nos remete aos PCN- Parâmetros Curriculares Nacionais que nos diz,

[...] a grande tarefa da escola é proporcionar um ambiente escolar saudável e coerente com aquilo que ela pretende que seus alunos aprendam, para que possa, de fato, contribuir para a formação da identidade como cidadãos conscientes de suas responsabilidades com o meio ambiente e capazes de atitudes de proteção e melhoria em relação a ele (PCN, 1998a, p.35).

Isso posto, deve-se almejar a procura de caminhos que ressaltem a diversidade entre as relações humanas, visando uma busca de qualidade de vida essencial a todos e esse processo deve ser realizado coletivamente, enfatizando as questões ambientais. (LIMA; MEYER; SILVA, 2011)

Entretanto, faz-se necessário discutir a interação da disciplina de Matemática com os temas ambientais, porém, a formação de pessoas capacitadas nas aulas de Matemática é necessária, desenvolvendo as atitudes do aluno, propiciando atividades à serem realizadas em grupos, o que estimula o desenvolvimento da capacidade de aplicar as ideias e refletir sobre as questões estudadas. (LIMA; MEYER; SILVA, 2011)

A elaboração dessa pesquisa, cujo tema é a “ A Matemática como Instrumento para a Educação Ambiental", fundamentou-se na leitura de artigos e livros procurando entender as visões de diferentes autores sobre o tema supracitado e foi desenvolvida durante todo o ano letivo de 2011 da Universidade do Vale do Sapucaí- MG.

Sendo assim surge a questão: Como a Matemática pode vir a contribuir para a Educação Ambiental? Desse modo, o objetivo deste artigo é mostrar como a Matemática pode auxiliar na conscientização da necessidade da preservação ambiental, discutindo, as maneiras como essa disciplina se insere nas diversas questões ambientais como, por exemplo, os cuidados com o lixo produzido, o desperdício de água, os cuidados com as áreas florestais, dentre outros aspectos, e teorizando sobre possíveis utilizações da matemática em sala de aula a fim de desenvolver no aluno o senso crítico e de responsabilidade social. (LIMA; MEYER; SILVA, 2011)

Como fundamento para desta pesquisa, foram utilizados os Parâmetros Curriculares Nacionais, de acordo com os quais a escola tem o papel de formar o aluno não só academicamente, mas também para exercer a cidadania, tornando-se pessoa mais crítica e sendo capaz de mudar sua própria realidade. (LIMA; MEYER; SILVA, 2011)

Também como pilar deste estudo, insere-se a Resolução de Problemas. Para Dante (1998), essa metodologia de ensino é muito trabalhada pelos educadores matemáticos, sendo para alguns a principal razão de se ensinar Matemática, porque através dela o aluno pode aplicar a matemática no cotidiano. 
Ainda de acordo com Dante (1998), a Resolução de Problemas torna-se necessária para os alunos na hora de enfrentar situações-problema.

Mais do que nunca, precisamos de pessoas ativas e participantes, que deverão tomar decisões rápidas e, tanto quanto possível, precisas. Assim, é necessário formar cidadãos matematicamente alfabetizados, que saibam como resolver, de modo inteligente, seus problemas de comércio, economia, administração, engenharia, medicina, e outros da vida diária (DANTE, 1998,p.15).

Dante (1998) ainda reforça que a resolução de problemas tem que ser uma iniciativa dos professores, podendo até ser usada como uma estratégia no ensino de Matemática, fazendo com que o aluno explore o tema abordado e justifique suas respostas, desenvolvendo a iniciativa e a criatividade dos alunos.

Como relata Onuchic (1999), trabalhar a aprendizagem com Resolução de Problemas é fazer com que o aluno seja capaz de relacionar Matemática com a variedade de contextos e problemas reais que fazem parte do seu dia-a-dia.

A Resolução de Problemas contribui para a construção do conhecimento, tendo como foco a participação do aluno, por isso deve-se refletir a melhor forma de trabalhar utilizando essa metodologia de ensino em sala de aula, para transformar o aluno em um cidadão participativo na sociedade (ONUCHIC, 1999).

\section{EDUCAÇÃO AMBIENTAL: CONCEITOS E ATITUDES}

O meio ambiente é o termo considerado pelo conhecimento geral como sinônimo de natureza, local que requer apreciação e respeito. Todavia, torna-se necessário aprofundar-se no entendimento desse termo, levando em conta o fato de que o ser humano pertence ao meio ambiente, e que é através dos recursos naturais que o mesmo garante sua sobrevivência (REBOUÇAS, 2009).

Ainda de acordo com Rebouças (2009), devido ao fato do termo "meio ambiente" poder ser designado como um território de várias espécies, todos os significados sobre esse termo tornam-se consideráveis para a pesquisa em educação ambiental. No sentido de ecossistema, o "Meio Ambiente" é um conjunto de ambientes reais, considerando-se sua complexidade e diversificação. Em relação à vida cotidiana, o meio ambiente é o lugar onde se vive, tal como casa, trabalho e escola. Como biosfera, pode ainda ser entendido como as sociedades ambientais e suas interdependências em todo mundo.

Estendendo um pouco mais a extensão do conceito de meio ambiente, tem-se que ele pode ser identificado como um completo conjunto de unidades ecológicas que funcionam como um sistema natural, mesmo com uma massiva intervenção humana e outras espécies do planeta, incluindo toda a vegetação, animais, microorganismos, solo, rochas, atmosfera e fenômenos naturais que podem ocorrer em seus limites, recursos e fenômenos físicos universais que não possuem um limite claro, como ar, água, e clima, assim como energia, radiação, descarga elétrica, e magnetismo, que não se originam de atividades humanas. Assim, o meio ambiente é o conjunto de condições externas onde um ser vivo ou comunidade consegue se desenvolver (ART apud DULLEY, 2004).

E foi através de pequenos grupos, os quais apontaram o tema meio ambiente como inclusão necessária em discussões sociais, que se obteve, a partir da década de 70, a devida atenção para as questões de conservação e preservação ambiental. Na década seguinte, novas sugestões para a preservação do meio ambiente surgiram em decorrência do crescimento de organizações não governamentais, entre as quais algumas que ajudaram a definir a legislação brasileira ambiental, ditando os rumos da preocupação e da ação ambiental. (LIMA; MEYER; SILVA, 2011)

Nucleus, v.9, n.2, out.2012 


\section{A NECESSIDADE DA EDUCAÇÃO AMBIENTAL}

No mundo atual, o desenvolvimento econômico é cada vez maior o que, consequentemente, interfere na preservação do meio ambiente. Assim, o modo de viver da sociedade com o desenvolvimento industrial e com o crescimento acelerado da população culmina com uma cada vez menor preocupação com o meio ambiente. Como consequência da falta de limite na exploração dos recursos naturais, surgiram grandes problemas ambientais que interferem na vida da sociedade. (GARCIA, 2011)

Segundo os PCN (1997), o aumento da população e a expansão industrial são a principal fonte de degradação do meio ambiente, pois à medida que os grandes centros urbanos crescem, o meio ambiente sofre uma selvagem invasão de construções civis e abusos desenfreados. Dentre essas violências, destacam-se o desmatamento, o crescimento desenfreado da população, a geração de favelas e, com isso, mais pobreza e violência, há também a contaminação de córregos com esgoto a céu aberto, dentre outros problemas ambientais e sociais.

Contudo, o problema ambiental não se resume somente aos grandes centros urbanos, mas também à zona rural, onde, na maioria das vezes, o uso de agrotóxicos para o combate de pragas nas lavouras é responsável pela contaminação da água de mananciais, tornando-os impróprios para o consumo. A mineração e a extração de recursos não renováveis é também uma ameaça para o meio ambiente, já que recursos como o petróleo, carvão mineral, entre outros estão, inevitavelmente, fadados a acabar. (LIMA; MEYER; SILVA, 2011)

Outro problema a ser considerado diz respeito ao acúmulo de lixo nos lixões, um dos resultados da crescente civilização atual, a qual produz cada vez mais lixo. Dessa forma, o lixo urbano torna-se um dos maiores problemas ambientais, causando mau cheiro, aumentando a procriação de animais transmissores de doenças, poluindo o ar e sendo também a principal causa da poluição do solo. (GARCIA, 2011)

Vale lembrar também que o Brasil possui vários recursos naturais de fundamental importância para todo o planeta. Dentre eles, destacam-se as florestas tropicais, como a Amazônica, o pantanal e o cerrado. É sabido que uma grande parte da água potável do mundo está em terras brasileiras, porém, é ainda pequeno o número de brasileiros que se preocupam com a correta utilização destes recursos. Convém destacar que a água limpa tem se tornado cada vez mais rara, fato que é resultado do desperdício da população, além de ser também um efeito colateral da poluição, da contaminação e das alterações climáticas provocadas pelo ser humano. (LIMA; MEYER; SILVA, 2011)

Esses problemas levaram países de todo planeta a ficarem preocupados com o Meio Ambiente. Na reunião do G-8 em 2007, na Alemanha, um dos temas mais discutidos foi a questão ambiental:

[...] O encontro entre os líderes do G8 terminado no início de junho de 2007 em Heiligendamm, na Alemanha, foi marcado pelas discussões sobre questões ambientais. As potências concordaram que é necessário reduzir as emissões de gases do efeito estufa para conter o aquecimento global (...) (VEJA,2007, s/p).

São inúmeras as causas que agridem o meio ambiente, e diante desse problema, faz-se necessário questionar se o desenvolvimento industrial e o avanço da civilização devem continuar desgastando um bem que é necessário ao próprio ser humano. De acordo com os problemas ambientais, tornam-se fundamentais mudanças no modo de agir e pensar em relação às questões ambientais. Porém, isso não é possível apenas com a lógica intelectual, pelo contrário; é necessário um processo de aprendizagem para conscientizar as pessoas do verdadeiro valor que tem a natureza, de acordo com os PCN do Meio Ambiente e Saúde: 
Nas nações mais industrializadas passa-se a constatar uma deterioração na qualidade de vida que afeta a saúde tanto física quanto psicológica dos habitantes das grandes cidades. Por outro lado, os estudos ecológicos começam a tornar evidente que a destruição - e até a simples alteração - de um único elemento num ecossistema pode ser nociva e mesmo fatal para o sistema como um todo (PCN, 1997, p.20).

Ainda para os PCN (1997), os recursos naturais e o meio ambiente são importantes componentes para o planejamento político, econômico e social dos governos que muito tem preocupado, com os problemas que podem acontecer por causa da degradação do meio ambiente.

Diante da polêmica ambiental que o mundo vivencia nos dias atuais, uma das soluções encontradas para uma diminuição da degradação do meio ambiente é a educação ambiental.

Isso nos remete a Ferreira (2010), que nos diz que,

[...] formar uma população mundial consciente e preocupada com o ambiente e com os problemas que lhe dizem respeito, uma população que tenha os conhecimentos, as competências, o estado de espírito, as motivações e o sentido de participação e engajamento que lhe permita trabalhar individualmente e coletivamente para resolver os problemas atuais e impedir que se repitam [...] (SERRA FILHO, 1987 apud FERREIRA, $2010, \mathrm{~s} / \mathrm{p})$.

Sendo assim, torna-se evidente a importância da educação dos futuros cidadãos brasileiros como empreendedores de modo que possam agir com responsabilidade e sensibilidade, atuando na conservação do meio ambiente saudável tanto no presente quanto no futuro. (LIMA; MEYER; SILVA, 2011)

Isso posto, nos remetemos a Furukawa (2008) que relata que é somente com consciência que cada indivíduo reconhecerá a real urgência e o grau de seriedade que deve encarar mudanças em seus hábitos e atitudes, no sentido de reduzir o desmatamento e destruição das florestas. Visando trabalhar o desenvolvimento dessa consciência, foram criados os temas transversais.

Vejamos.

\section{TEMAS TRANSVERSAIS}

A reunião de disciplinas como Meio Ambiente, Ética, Saúde, Trabalho e Consumo, Pluralidade Cultural, foi intitulada "Temas Transversais". Tão importantes quanto os conteúdos escolares convencionais, os temas transversais buscam apresentar questões sociais para a educação do cidadão. É importante ressaltar que o currículo torna-se flexível e aberto a novos temas que possam vir a ser inseridos e contextualizados, baseados nas condições reais de diferentes locais e regiões. (PCN, 1998c).

É preciso ressaltar a importância do acesso ao conhecimento socialmente acumulado pela humanidade. Porém, há outros temas diretamente relacionados com o exercício da cidadania, há questões urgentes que devem necessariamente ser tratadas, como a violência, a saúde, o uso de recursos naturais, os preconceitos, que não tem sido diretamente contemplados por essas áreas. Esses temas devem ser tratados pela escola, ocupando o mesmo lugar de importância (apud SILVA, REIS, OLIVEIRA, 2009, p.15).

A inclusão de questões em que a crítica e a compreensão da realidade são possíveis ao pensamento e não tratadas abstratamente aprimora a reflexão e contribui nas mudanças para a própria existência do cidadão. Contudo, a maneira como o professor organiza as atividades educativas e as opções didáticas que ele usa, fazem com que se ensinem atitudes e valores da sociedade. No desejo de uma transformação, aprender e ensinar torna-se cúmplices na formação de um conjunto de superação para o conhecimento. (apud SILVA; REIS; OLIVEIRA, 2009). 
Portanto, com os Temas Transversais, a aprendizagem escolar passa a ser valorizada, deixa de ser vista apenas como necessidade para "passar de ano" e agora oferece razão a conceitos convencionais das áreas escolares. (PCN, 1998c).

Segundo os PCN (1997), para a elaboração dos Temas Transversais, o MEC se utilizou de critérios para salientar, dentre as múltiplas questões sociais, as que mais precisam ser abordas em sala de aula, as quais sejam:

- Urgência Social: quem tem como objetivo principal abordar questões sociais que possam colocar em risco a dignidade do cidadão;

- Abrangência Nacional: questões que acontecem em todo Brasil;

- Possibilidade de ensino aprendizagem no ensino fundamental: buscam questões sociais que favorecem esta etapa de vida do aluno embora, o Brasil não tenha uma educação uniforme;

- Favorecer a compreensão da realidade e a participação social: busca desenvolver no aluno a capacidade de ver, agir e intervir que seja capaz de superar os problemas que possa vir a enfrentar (PCN, 1997).

Com base nesses critérios colocados acima, a educação ambiental desponta como um Tema Transversal que deve trabalhado pelo professor dentro de sala de aula com o objetivo de auxiliar os alunos a desenvolverem os valores necessários a uma vida como cidadãos (PCN, 1997).

Já o desenvolvimento sustentável surgiu da necessidade de multiplicar as práticas sociais ligadas à educação ambiental, aumentando as iniciativas de um maior acesso às informações sobre os problemas ambientais urbanos, implicando uma organização na administração das autoridades competentes. Coube assim ao poder público incrementar os conteúdos educacionais e criar caminhos para alterar o quadro atual da degradação socioambiental (JACOBI, 2003).

Reiterando essa necessidade de ação, Carvalho e Viana (1998) afirmam que a sustentabilidade ambiental só desempenhará seu papel se os recursos naturais forem utilizados de maneira consciente pelas empresas, substituindo os recursos não renováveis pelos recursos renováveis e desenvolvendo tecnologias limpas, além de uma ação mais prestativa de órgãos públicos na defesa do meio ambiente (apud ARAÚJO, et al, 2006).

\footnotetext{
O momento atual exige que a sociedade esteja mais motivada e mobilizada para assumir um caráter mais propositivo, assim como para poder questionar de forma concreta a falta de iniciativa dos governos para implementar políticas pautadas pelobinômio sustentabilidade e desenvolvimento numcontexto de crescentes dificuldades para promover ainclusão social. Paratanto é importante o fortalecimento das organizações sociais e comunitárias, a redistribuição de recursos mediante parcerias, de informação e capacitação para participar crescentemente dos espaços públicos de decisão e para a construção de instituições pautadas por uma lógica de sustentabilidade (JACOBI, 2003, p.189).
}

Sendo assim, a sustentabilidade deve ser foco de um novo perfil de desenvolvimento, uma vez que, analisando o contexto atual das práticas sociais, podemos perceber que a degradação permanente vem marcando de maneira forte nosso meio ambiente. O desenvolvimento sustentável é uma estratégia da sociedade para uma adequação ecológica, ligando sociedade humana e natureza, sendo a passagem do conceito para a ação. (JACOBI, 2003).

Após estas considerações, passaremos a destacar a Matemática como instrumento para a Educação Ambiental. 


\section{A MATEMÁTICA COMO INSTRUMENTO PARA A EDUCAÇÃO AMBIENTAL}

Tendo em mente a importância da Educação Ambiental e a urgência de sua prática e divulgação, fica claro que é necessária sua prática entre as disciplinas, pois a interdisciplinaridade como forma de cooperação enriquece o tema abordado (DIAS, 1994).

Segundo Pedrini (1998), como a Educação Ambiental transcende as áreas trabalhadas na escola de maneira formal, não sendo definida como uma área do conhecimento especializado, não existe a obrigação de sua inclusão como uma das disciplinas do currículo, mas é necessária sua constante presença em cada disciplina, como um tema transversal (apud THOMAS, 2009).

Neste sentido, tem-se tornado, cada vez maior, a necessidade de que a Matemática, como disciplina escolar, acompanhe a evolução da sociedade e, da própria ciência (FILIPPSEN, 2003 apud THOMAS, 2009).

Para Filippsen (2003), a Matemática e Educação Ambiental estão diretamente interligadas. Essa intersecção é capaz de ajudar os alunos a formar hábitos e identificar os problemas que estão degradando o meio ambiente. Desse modo, se os conteúdos de matemática forem bem desenvolvidos e aprofundados, o aluno desenvolverá uma visão mais crítica da sociedade na qual está inserido. Nesse sentido, é dever do professor de matemática ser mediador ajudando os alunos a se tornarem cidadãos mais críticos, através de projetos utilizando-se de jornais e revistas, entre outros. Dessa forma, é possível aproximar a matemática da realidade do aluno.

Praticamente tudo o que se nota na realidade dá oportunidade de ser tratado criticamente com um instrumental matemático. Como um exemplo, temos os jornais, que todos os dias trazem assuntos que podem ser explorados matematicamente. Oque se pede aos professores é que tenham coragem de enveredar por projetos (D’AMBRÓSIO, 1996, p.98 apud FILIPPSEN, 2003, p.4).

Os aspectos quantitativos e qualitativos envoltos no interior da Matemática são fundamentais para a compreensão de um fenômeno ambiental. Isto é, "quantificando problemas ambientais, teremos uma visão mais significativa do fenômeno que está ocorrendo no ambiente." A Matemática pode oferecer métodos, ferramentas e procedimentos para a análise quantitativa de questões ambientais. (CALDEIRA, 2003).

Para D’Ambrósio (2001 p.17),

A questão ambiental se apresenta com urgência como tema central dos programas escolares. Dificilmente, essas questões poderão ser abordadas sem matemática. Isso implica a apresentação de novos conteúdos e metodologias que permitam capacitar o aluno para o fazer matemático, como aquilo que a modelagem possibilita (apud MIYASAKI, 2008).

De acordo com Toledo (1997), devem ser envolvidos aspectos, além das aplicações de operações nos problemas matemáticos, pois a Educação deve voltar-se para o desenvolvimento do indivíduo, para que o mesmo seja capaz de selecionar informações de maior utilidade para o seu dia a dia, analisando e criticando as informações recebidas (apud SANTOS, TELES, 2011).

Com o auxílio da matemática, pode-se trabalhar com os alunos em sala de aula temas como o aquecimento global, a produção de lixo nos grandes centros urbanos, a reciclagem de materiais, o desmatamento, dentre outros. Sendo assim, a construção ou interpretação de gráficos, porcentagem, 
médias e demais ferramentas matemáticas vêm auxiliar os alunos na compreensão dos dados obtidos. (GARCIA, 2011)

É preciso que a matemática seja encarada com maior significância para que haja melhora na compreensão das ciências que interagem entre si e na complementação que uma traz para a outra. Desse modo, através de reflexões sobre variadas situações, a Matemática oferece um olhar crítico em relação ao nosso meio. "Aprender e usar Matemática no seu cotidiano faz com que o estudante perceba, entre outras coisas, seu verdadeiro papel como cidadão e transformador social” (CALDEIRA, 2003).

A Matemática torna-se importante devido a seu papel decisivo na resolução de problemas do diaa-dia. Ela funciona como instrumento essencial na aplicação de outras áreas do currículo escolar (PCN, 2000).

Transformar a realidade do aluno trata-se de investir na construção de seu conhecimento, fazendo com que o mesmo tenha uma visão mais crítica do mundo no qual está inserido. Sendo assim, é prioridade que o docente ressalte as ferramentas matemáticas para todas as áreas de estudo (PCN, 2000).

No ensino da Matemática, destacam-se dois aspectos básicos: um consiste em relacionar observações do mundo real com representações (esquemas, tabelas, figuras); outro consiste em relacionar estas representações com princípios e conceitos matemáticos. Nesse processo, a comunicação tem grande importância e deve ser estimulada, levandose o aluno a "falar" e a "escrever" sobre matemática, a trabalhar com representações gráficas, desenhos, construções, a aprender como organizar e tratar dados (PCN, 2000, p. 19)

Como ferramenta metodológica, é importante ressaltar o uso da resolução de problemas no ensino aprendizagem de Matemática que propiciam a formação do aluno como cidadão crítico e atuante na sociedade. (LIMA; MEYER; SILVA, 2011)

Segundo Dante (2002), o professor deve criar metodologias para fazer com que o aluno pense produtivamente e sinta-se desafiado a resolver problemas. Também é fundamental desenvolver no aluno o seu raciocínio lógico através do uso de metodologias que propiciem esse desenvolvimento. Para esse autor,

Através de conceitos, técnicas e procedimentos matemáticos procura-se matematizar uma situação real, organizando os dados. Podem ser apresentados em forma de projetos a serem desenvolvidos usando conhecimento e princípios de outras áreas que não a matemática, desde que a resposta se relacione a algo que desperte interesse (2002, p. 20).

Também refere-se à aprendizagem Polya (1887), para quem o aluno deve aprender a ser independente, porém se ele for deixado sozinho, pode não apresentar progresso algum. Assim, o professor não pode auxiliar seus alunos demais, nem muito pouco, mas sim de modo que os mesmos fiquem com uma parcela razoável do trabalho.

Segundo os PCN (1998b), a Matemática só passa a ter significado para o aluno se ele encontrar situações problema que o envolvam e o desafiem a formular estratégias para resolvê-los. Porém, na prática não é bem assim, os problemas são utilizados apenas como forma de aplicar os conteúdos já estudados. Ou seja, problema, não é aquele em que o aluno resolve de forma quase que mecânica um processo operatório, mas sim aquele que leva o aluno a pensar, interpretar o enunciado da questão, para depois criar uma estratégia de resolução.

A Matemática não é uma ciência que anda sozinha, trata-se de uma disciplina que está interligada às demais. Por isso, os professores de Matemática devem fazer com que suas aulas sejam contextualizas e 
dinâmicas, para que o aluno possa aplicar de forma concreta o que aprendeu. (LIMA,; MEYER; SILVA, 2011)

Sendo assim, a matemática e a Educação Ambiental podem ser trabalhadas de maneira interligada por meio de problemas contextualizados, pois ao mesmo tempo em que abordam os conceitos matemáticos, reforçam para os alunos a necessidade da preservação ambiental, a qual é responsabilidade de todos os seres humanos. (LIMA; MEYER; SILVA, 2011)

Nesse sentido, serão apresentados a seguir alguns problemas contextualizados envolvendo meio ambiente e Matemática, os quais foram desenvolvidos com o intuito de auxiliar os professores ou profissionais de áreas afins que venham dele tomar conhecimento. De maneira a torná-los contextualizados, os enunciados apresentados abaixo foram retirados de artigos de revistas, sendo as perguntas dos problemas elaboradas pelos pesquisadores. (LIMA; MEYER; SILVA, 2011).

Convém frisar que a finalidade destes problemas, conforme objetivos propostos no início deste artigo, é apresentar conceitos relativos ao tema meio ambiente, mostrando, através de diversas aplicações, como a Matemática pode contribuir com a Educação Ambiental.

Vejamos.

Problema 1. Nas empresas do grupo Votorantin, $60 \%$ da energia consumida é de fontes renováveis, com $68 \%$ da energia autogerada. (Veja, 2011, p. 117).

\section{Figura 1}

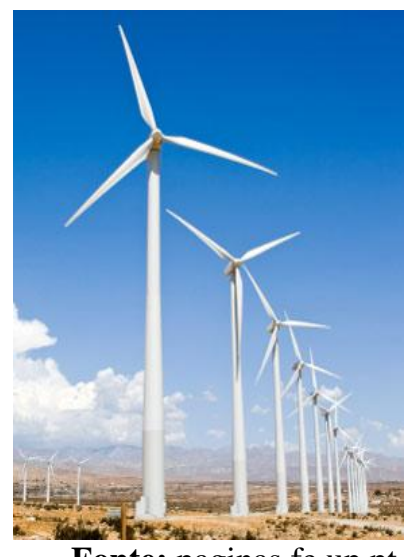

Pede-se:

a) Expressar essas porcentagens na forma decimal.

b) Em sua opinião, essa empresa está aplicando a sustentabilidade?

Problema 2. Se o aquecimento das águas do oceano se mantiver ao ritmo de 0,1 grau por década, em 60 anos teremos o dobro das tempestades em SP e RJ. (Veja, 2011, p. 125).

Figura 2

a) Transforme 0,1 em número fracionário.

b) O que significa dobrar as tempestades?

c) $\mathrm{O}$ que você pensa sobre o aquecimento global?

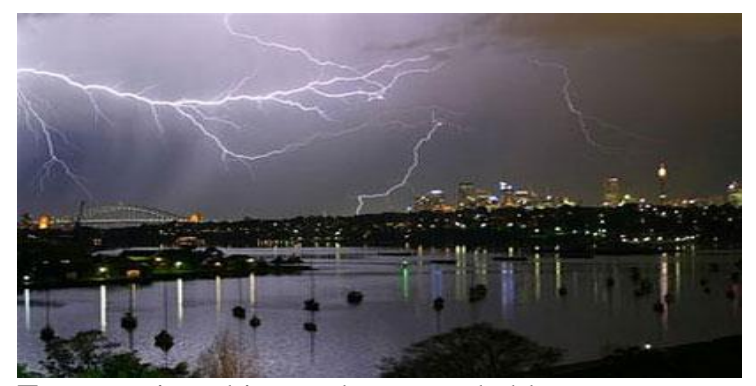

Fonte:meioambiente-planetaverde.blogspot.com 
Problema 3. Para o planeta, em 2010, seus nove primeiros meses foram os mais quentes desde que começaram os registros, há 131 anos. (Época, 2010, p. 120).

Figura 3

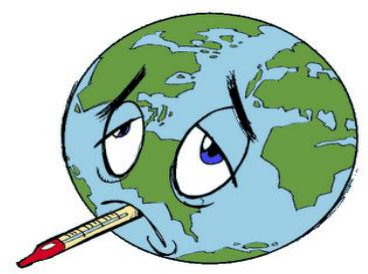

a) Qual a porcentagem de meses mais quentes em 2010?

b) Em sua opinião, quais fatores contribuíram para esse aumento de temperatura?

Fonte: pensareco.blogspot.com

Problema 4. Na última década, a produção brasileira de petróleo cresceu $60 \%$, a maior alta entre as dos vinte grandes produtores. (Veja, 2011, p. 54).

Figura 4

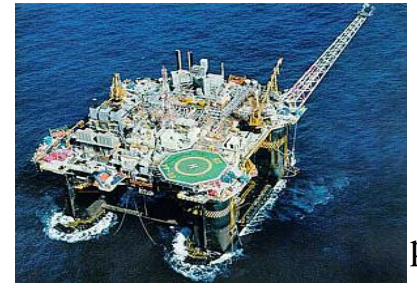

Fonte: jornale.com.br

\section{Responda}

a) Quantos são os anos referentes à década anterior?

b) O que significa um aumento de $60 \%$ ?

c) Em sua opinião, qual a importância desse aumento na produção de petróleo brasileiro?

d) $\mathrm{O}$ que você pensa sobre o aumento dessa produção e a preservação do meio ambiente?

Problema 5. Há estudos revelando que populações carentes, moradoras em locais sem água encanada, consomem cerca de 30 litros todos os dias. Já quem mora em apartamentos ou casa com máquinas de lavar roupa e louça chega a gastar 500 litros. (Isto é, 2007, p. 83).

Figura 5

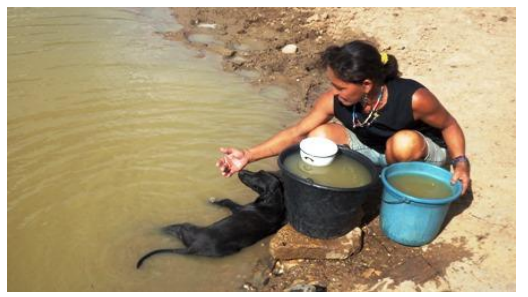

Fonte: calilanoticias.com b) As populações carentes consumirão 4700 litros de água a menos que as populações com melhores condições financeiras.

b) As populações carentes consumirão a mesma quantidade de água que as de melhores condições financeiras.

\section{Figura 6}

Problema 6. Escovar os dentes por 5 minutos:

- Com a torneira aberta, gastam-se 12 litros.

- Com a torneira fechada se gasta 1 litro. (SGARBI, 2007, p. 84).

Levando-se em consideração que o ser humano faz sua higienização nos dentes 4 vezes ao dia, pergunta-se:

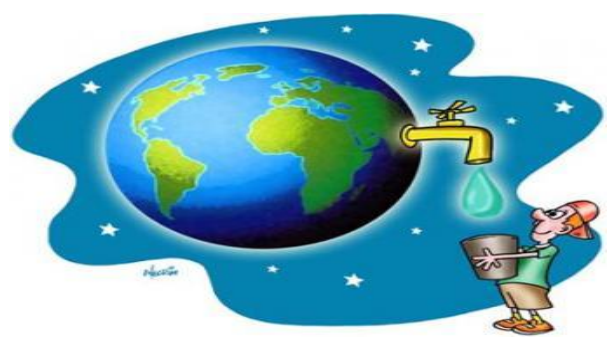

Fonte: salveoplanetaeleprecisa.blogspot.com 
a) Quantos litros de água serão consumidos por dia pela pessoa que escovar seus dentes com a torneira aberta?

b) Qual será o consumo em litros por dia, da pessoa que fechar a torneira para escovar seus dentes?

c) Qual das duas pessoas está agindo corretamente? Por quê?

Problema 7. Utilizadas principalmente por Indústrias de refrigerantes e sucos, as garrafas Pets movimentam hoje um mercado que produz cerca de 9 bilhões de unidades anualmente só no Brasil, das quais 53\% não são reaproveitadas. Com isso, cerca de 4,7 bilhões de unidades por ano são descartadas na natureza, contaminando rios, indo para lixões ou mesmo espalhadas por terrenos vazios. (TAGORE, 2008, s/p). $\quad$ Figura 7

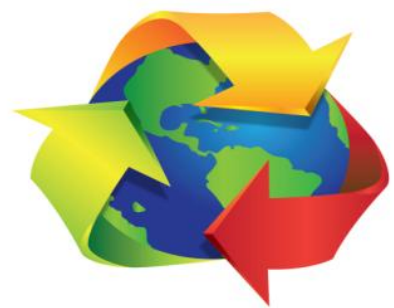

Pede-se:

a) A quantidade em bilhões e a porcentagem de garrafas Pets que são recicladas anualmente no Brasil.

b) Uma sugestão em relação ao reaproveitamento de garrafas Pets.

Fonte: ocondominio.wordpress.com

Problema 8. Os números apresentados pela CNA (Confederação Nacional da Agricultura)para questionar a aplicação do código florestal são assustadores.

Figura 8

Segundo eles, se as leis fossem cumpridas a soma de todas

As áreas protegidas, como parques, reservas indígenas e reservas legais, ocupariam $71 \%$ do território nacional. (MANSUR, 2010, p. 42).

a) Determine a porcentagem restante que poderia ser usado para a agricultura e cidades.

b) Hoje, no entanto, $44 \%$ do território estariam ocupados para esses usos. Se o país fosse se adequar à lei,quanto os agricultores teriam de abrir mão da área ocupada?

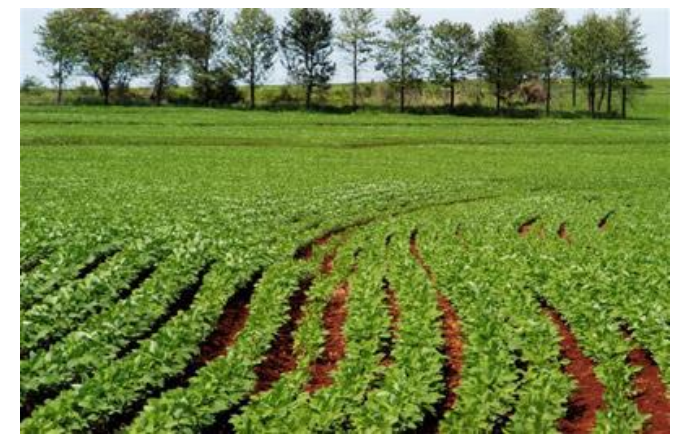

Fonte: newscomex.com.br

Problema 9. O estado de Mato Grosso, responde por mais de um terço do desmatamento do país. Nos últimos seis anos, a Secretaria Estadual de Meio Ambiente começou a cadastrar as áreas de preservação dos proprietários. Já registrou oito mil propriedades, que correspondem a 30\% da área total do estado.(MANSUR,2010, p. 43). Com base nesses dados, determine: $\quad$ Figura 9

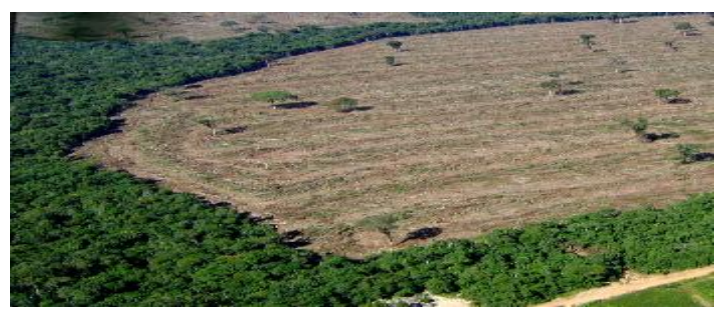

Fonte: jpmabrasil.wordpress.com a) A fração que é referida no texto.

b) A porcentagem de área restante do Estado de Mato

Grosso sem registro de propriedade, valor numérico (próximo) de propriedades que ainda não foram registradas. 
Problema 10. Há 55 milhões de anos, a temperatura subiu 6 graus. Em 20 mil anos houve grandes extensões. Agora a temperatura pode subir o mesmo tanto em apenas 200 anos. (MANSUR, 2009, p. 115).

Qual será a média da temperatura em graus que aumentará por ano?

Isso posto, convém destacarmos que estes são alguns problemas que frisam diversos conceitos matemáticos aplicados, fato que demonstra como a Matemática contribui para a Educação Ambiental.

\section{CONSIDERAÇÕES FINAIS}

Esse artigo foi realizado com o objetivo de apresentar aos leitores, conceitos gerais sobre o meio ambiente, ressaltando a importância de inserir a Educação Ambiental por meio da disciplina Matemática no contexto escolar.

E diante dos problemas atuais, os quais envolvem o meio ambiente, destacou-se a necessidade de se trabalhar em sala de aula a conscientização dos alunos para a preservação ambiental, visto que essa questão pode ser inserida nas diversas disciplinas escolares, em especial, a Matemática, a qual nos fornece subsídios qualitativos e quantitativos para esta ação.

Também, por meio deste artigo, mostrou-se que a Educação Ambiental pode ser trabalhada em sala de aula, por meio da disciplina de Matemática. E através da Resolução de Problemas, pode-se conhecer, interpretar e resolver problemas contextualizados envolvendo o tema meio ambiente.

Nesse sentido, conclui-se que a utilização da Matemática como ferramenta para o estudo de questões ambientais, torna-se instrumento para a compreensão dos temas que envolvem o meio ambiente, possibilitando ao aluno uma visão crítica da realidade atual, podendo assim tornar-se cada vez mais consciente da necessidade de construir uma sociedade sustentável e ativa no que diz respeit $\quad$ oteção do nosso planeta.

\section{REFERÊNCIAS}

ARAÚJO, G. C; BUENO, M.P; SOUSA, A. A; MENDONÇA, P. S. M. Sustentabilidade Empresarial: conceito e indicadores. Disponível em:http://www.convibra.com.br/2006/artigos/61_pdf.pdf III

CONVIBRA - 24 a 26 de novembro de 2006. Acesso em 29 de maio de 2011.

BIACHINI, E. Matemática $6^{0}$ Série. $3^{\text {a }}$ edição. São Paulo: Editora Moderna.

BOFF, LEONARDO. Carta da Terra. Disponível em: http://radeir.blogspot.com/2010/08/carta-da-terraleonardo-boff.html . Acesso em 01 dez. 2010.

BRASIL, MINISTÉRIO DA EDUCAÇÃO E CULTURA. Parâmetros curriculares nacionais. Brasília: MEC/SEF, 1996.

BRASIL, MINISTÉRIO DA EDUCAÇÃO E CULTURA. Parâmetros curriculares nacionais. Brasília: MEC/SEF, 1997.

. Secretaria de Educação Fundamental. Parâmetros Curriculares Nacionais:

Matemática. Brasília: MEC/SEF, 1998a.

Secretaria de Educação Fundamental. Parâmetros Curriculares Nacionais: Meio

Ambiente e Saúde. Brasília: MEC/SEF, 1998b. 
Secretaria de Educação Fundamental. Parâmetros Curriculares Nacionais:

Apresentação dos Temas Transversais. Brasília: MEC/SEF, 1998c.

BRASIL, Secretaria de Educação Fundamental. Parâmetros Curriculares Nacionais: Matemática. Brasília: MEC/SEF, 2000.

CALDEIRA, A. D. Educação Ambiental e suas implicações na Formação do Professor de

Matemática. Disponível em: http://www.revistas.uniube.br/index.php/rpd/article/view/27. Acesso em 10 de Agos. de 2011.

CARTA DA TERRA. Disponível em:

http://www.movimentodasartes.com.br/joseantonio/download/Cartadaterra.pdf. Acesso em: 19 de out. 2011.

CARVALHO, E. Globo Natureza. Disponível em:

http://g1.globo.com/natureza/noticia/2011/08/industria-nacional-se-mobiliza-para-reduzir-emissao-de-co2atmosfera.html. Acesso em 05 de out. 2011.

DANTE, L. R. Didática da Resolução de Problemas de Matemática. 12 ed. São Paulo: Editora Ática, 1998.

DANTE,L.R.Didática da Resolução de Problemas.12 ed.SãoPaulo:Editora Ática,2002.

DANTE, L, R. Matemática, volume único: livro do professor. $1^{\circ}$ ed. São Paulo: Ática, 2005.

DIAS, G, F. Atividades interdisciplinares de Educação Ambiental: manual do professor.São Paulo: Editora Global/Gaia, 1994.

DUARTE, P, C, X. Desenvolvendo Cidadãos Atuantes Por Meio do Ensino e Aprendizagem da Matemática. São Paulo: Porto de Idéias Editora, 2010.

DULley, R, D. Natureza, Ambiente, Meio Ambiente, Recursos Ambientais e Recursos Naturais. Disponível em: http://www.iea.sp.gov.br/out/publicacoes/pdf/asp-2-04-2.pdf. Acesso em 02 de Abr. 2011.

FILIPPSEN, R. M. J. Educação Matemática e Educação Ambiental: educando para o desenvolvimento sustentável. Disponível em: http://www.liberato.com.br/upload/arquivos/0131010716351516.pdf. Acesso em 15 de agosto de 2011.

FERREIRA, M, C, C. Educação Ambiental e a Sensibilização Ecológica na Construção da Cidadania. Disponível em: http://www.jurisway.org.br/v2/dhall.asp?id_dh=3866. Acesso em: 13 de mar. 2011.

FURUKAWA, M. Educação Ambiental: a formação do cidadão consciente. Disponível em: http://ajudasc.blogspot.com/2008/12/educacao-ambiental-formao-do-cidadao.html. Acesso em 13 de mar. 2011.

GARCIA, L. C. Desenvolvendo a matemática como instrumento para a preservação do meio ambiente. 2011. Projeto PIBIC-Jr. UNIVÁS- MG/ FAPEMIG- MG

GIOVAnNI, J, R; CASTRUCCI, B; GIOVANNI,J, R, J. A conquista da Matemática- Nova. São Paulo: FTD, 1998.

JACOBI, P. Educação Ambiental, Cidadania e Sustentabilidade. Disponível em: www.scielo.br/pdf/cp/n118/16834.pdf. Acesso em: 27 de set. 2011. 
LIMA, A. E; MEYER, V.M da S; SILVA, N. de A. A Matemática como instrumento para a educação ambiental. 2011. Trabalho de Conclusão de Curso (Licenciatura em Matemática): Universidade do Vale do Sapucaí -UNIVÁS- Pouso Alegre- MG

LÜDKE, M; ANDRÉ, M. E. D. A. Pesquisa em Educação: abordagens qualitativas. Editora EPU Ltda. São Paulo. 1988. $9^{\text {a }}$ reimpressão.

MANSUR, A. É possível plantar sem desmatar. Revista Época. São Paulo: Editora Globo S.A. 12 de Outubro de 2010. № 595.

MANSUR, A. O aquecimento global vai ser bom. Revista Época. São Paulo: Editora Globo S.A. 7 de Setembro de 2009. N $^{\circ} 590$.

MARCATTO, C. Educação ambiental: conceitos e princípios. Belo Horizonte: FEAM, 2002. Disponível emhttp://www.scribd.com/doc/7028363/Educacao-Ambiental-Conceitos-Principios. Acesso em 13 de março, 2011.

MIYSAKI, D, M . Modelagem Matemática e Educação Ambiental: possibilidades para o ensino fundamental. Disponível em: http//WWW.diaadiaeducacao.pr.gov.br/portals/pde/arquivos/359-4.pdf. Acesso em 06 de jun. 2011.

ONUCHIC, L. R. Ensino-aprendizagem de Matemática através da Resolução de Problemas. In: BICUDO, M. A. V. (org.). Pesquisa em Educação Matemática: concepções e perspectivas. São Paulo: Editora UNESP, 1999.

PELEGRINI, A, F; FIGUEIREDO, D, M. Educação Ambiental e o ensino de Matemática: uma Prática metodológica na $5^{\text {a }}$ série do ensino fundamental. Disponível em:http://www.ufmt.br/revista/arquivo/rev14/educacao_ambiental_e_o_ensino_de.html. Acesso em 06 de jun. 2011.

POLYA,G. Aarte de resolver problemas: um enfoque do método matemático. Tradução e asptação de Heitor Lisboa de Araújo. Rio de Janeiro: Interciência, 1994.

PRESIDÊNCIA DA REPÚBLICA DA CASA CIVIL SUBCHEFÍA PARA ASSUNTOS JURÍDICOS. Lei no 9.605. Disponível em: http://www.planalto.gov.br/ccivil_03/Leis/L9605.htm. Acesso em 02 Abr. 2011.

REBOUÇAS, F. Conceito de Meio Ambiente. Disponível em: http://www.infoescola.com/geografia/conceito-de-meio-ambiente. Acesso em 31 de mar. de 2011.

REVISTA ECOLÓGICO. Edição Total Lua Cheia. Ano 3, volume 30, 19 de mar. 2011.

REVISTA ISTO É. 21 de Março2007. №1951. Ano 30.

REVISTA VEJA. Edição2224. Ano 44, Editora Abril, 06 de julho de 2011.

REVISTA VEJA. Edição2229. Ano 44, Editora Abril, 10 de agosto de 2011.

REVISTA VEJA ON LINE. Disponível em:

http://veja.abril.com.br/idade/exclusivo/perguntas_respostas/reuniões_g8/índex.shtmlde2007. Acesso em: 12 mar. 2011.

RIBEIRO, A. A Chance de Cancun.Revista Época. São Paulo. Editora Globo S.A.29 de Novembro de 2010.

SGARBI, L. Por uma Gota.Revista Isto É. São Paulo: Editora Três Ltda. 21 de Março de 2007. Nº1951. Ano 30. 
SILVA, C, A, S; REIS, S, P ;OLIVEIRA, V, D. A Matemática e os Temas transversais. Pouso Alegre: Univás/ FAFIEP, 2009.

SANTOS, D,C,S; TELES, A,M. Análise dos Livros Didáticos de Matemática do $1^{\circ}$ ao $5^{\circ}$ ano do Ensino Fundamental: contextualização entre os conteúdos matemáticos e o Tema Transversal Meio Ambiental.Disponível em: http://www.sbemrn.com.br/site/II\%20erem/comunica/doc/comunica29.pdf. Acesso em 06 de jun. 2011.

TAGORE, V. Revista Meio Ambiente online. Disponível em:

http://www.revistameioambiente.com.br/2008/03/17/sem-reciclagem-brasil-descarta-47-bi-de-garrafaspet-na-natureza/. Acesso em: 20 de Set. 2011.

THOMAS, M, I, P. O Desafio de Novos Autores Comprometidos com a Matemática e a Educação Ambiental. Disponível em:

http://www.projetos.unijui.edu.br/matematica/cd_egem/fscommand/RE/RE_46.pdf. Acesso em 06 de junho de 2011. 
